\title{
The Pengchiayu Volcano: A Holocene Surtsey-Type Eruption in North Offshore Island of Taiwan
}

\author{
Sheng-Rong Song ${ }^{1}$ and Yi-Chia $\mathrm{Lu}^{2}$ \\ ${ }^{1}$ Department of Geosciences, National Taiwan University, Taipei 106, Taiwan, \\ srsong@ntu.edu.tw \\ ${ }^{2}$ Institutes of Oceanography, National Taiwan University, Taipei 106, Taiwan, \\ d00224007@ntu.edu.tw
}

\begin{abstract}
The Surtsey-type eruption, an explosive volcanism occurred in the Surtsey Volcano, south Iceland in 1961, is characterized by the magma-water interaction, named hydrovolcanism, to cause strong explosion in shallow marine environment. It provides us to understand how an eruption proceeds and characteristics of products occurred transition from shallow marine to subaerial. The Pengchiayu, located at the offshore island in north Taiwan, is a volcanic island with controversial eruptive ages ranging from 2.1 Ma to less than 0.29 Ma, dated by K-Ar method. Geomorphologically, a crater with diameter about $50 \mathrm{~m}$ wide and fresh reddish scoria in top crops out in northwest tip, and a depression, probably was a tuff cone, occurs in central part of the island. Geologically, well bedded base surges with thickness totally over $30 \mathrm{~m}$ thick and ranging from few to tens of centimeters expose in southeast and west island. The lava flows with Aa and pahoehoe structures cover on the top or outflow from a breach of cone to the south and the north. Meanwhile, glassy scoria shows very fresh characters and almost no weathering on surface. In addition, a whole-coring about $100 \mathrm{~m}$ deep has been drilled and showed the lithology being composed of the thick lavas with vesicles, reddish scoria, weathered soils, base-surges and lavas from bottom to top. This sequence infers that the eruptions occurred in subaerial condition firstly, then the hydrovolcanism followed to produce thick base surges in shallow marine, and finally erupted in subaerial again. Combining several lines of evidence from surface observations and drilled core records, the last activity of pengchiayu volcano was a surtsey-type eruption and occurred probably in latest glacial sea level rising, which is in the Holocene period.
\end{abstract}

